Diagnóstico ambiental e avaliação da capacidade de suporte das praias do bairro de Itapoã, Salvador, Bahia Iracema Reimão Silva, José Rodrigues de Souza Filho, Merissa Andrade Leite Barbosa, Fádia Rebouças, Ricardo Augusto Souza Machado

\title{
DIAGNÓSTICO AMBIENTAL E AVALIAÇÃO DA CAPACIDADE DE SUPORTE DAS PRAIAS DO BAIRRO DE ITAPOÃ, SALVADOR, BAHIA
}

\section{Environmental diagnosis and capacity analyzes of Itapoã's neighborhood, Salvador, Bahia}

\author{
Dra. Iracema Reimão Silva \\ Professora da Universidade Federal da Bahia \\ Pesquisador Nível 2 do CNPq \\ Salvador/BA - Brasil \\ José Rodrigues de Souza Filho \\ Professor Faculdade de Tecnologia e Ciência \\ Salvador/BA - Brasil \\ Merissa Andrade Leite Barbosa \\ Graduação em Geografia da Universidade Católica do Salvador \\ Salvador/BA - Brasil \\ Fádia Rebouças \\ Mestrando em Geografia da Universidade Federal da Bahia \\ Salvador/BA - Brasil \\ Ricardo Augusto Souza Machado \\ Professor da Universidade Católica de Salvador \\ Salvador/BA - Brasil
}

Artigo recebido para publicação em 01/08/2008 e aceito para publicação em 30/01/2009

RESUMO: $\quad$ O bairro de Itapoã, por seus importantes recursos naturais e grande valor cultural, apresenta um capital simbólico que o destaca dos outros bairros de Salvador. Devido aos seus diversos atrativos, foi um dos principais locais de veraneio em meados do século passado e, nas últimas décadas, vêm sofrendo um processo de urbanização acelerada, resultando na superlotação das praias, poluição e destruição da vegetação nativa. Neste contexto, este artigo pretende avaliar a capacidade de suporte das praias do bairro de Itapoã, de acordo com os limites de tolerância dos seus usuários, fornecendo subsídio para a sua gestão sócio-ambiental. As praias de Itapoã foram divididas em 55 células com $30 \mathrm{~m}$ de comprimento e, a partir do cálculo da área de cada célula e do número de usuários em cada uma delas, foi estimada a área disponível para cada banhista/recreacionista. A maior parte das praias do bairro estudado apresentou um uso intenso, com 4 a $10 \mathrm{~m}^{2}$ por banhista/recreacionista, aqui considerado como o limite de tolerância para os usuários destas praias. Durante as entrevistas, a sujeira e a falta de estrutura das barracas foram os principais problemas apontados, enquanto que, a facilidade de acesso e a tranqüilidade foram os principais atrativos para a maior parte dos entrevistados.

Palavras-chave: Capacidade de suporte. Gestão socioambiental. Urbanização. 
ABSTRACT: Itapoã's neighborhood is best known for its natural resources and enormous cultural value. It represents the city symbol, its unique features differentiates it from others neighborhoods. Due to its diverse attractions, in the past century, Itapoã was the most popular summer resort. But in the past decades, due to accelerated urbanization process, it became a place with overcrowded beach, high levels of pollution and destruction of native vegetation. In this context, this article intends to analyze the capacity of support and accommodation of regular attendants of Itapoã's beach, giving subsidizes to its environmental and social management. Itapoã's beach was divided in 55 equal units of 30 meters length. The numbers of person occupying each area was used to calculate the area at disposition for each user. The major parts of this neighborhood area showed an intense density, living 4 to 10 meters square per user. This area per person represents the minimum area tolerated by the users. During the interviews, the dirt and lack of structures from the beach establishments were the worst problems pointed out, while the easy access and peace were the most attractive.

Keywords: Capacity of support. Environmental and social management. Urbanization process.

\section{Introdução}

Atualmente, as praias têm-se destacado como um dos ambientes naturais mais procurados pelos turistas em todo o mundo, confirmando a preferência recreacional de turismo e de lazer pelo modelo "sol, areia e mar" (VERA et al., 1997; KULLENBERG, 2001; HALL, 2001; MIDAGLIA, 2001; MAC LEOD et al., 2002; ERGIN et al., 2006). O aumento da utilização das praias para fins recreacionais é também o resultado da percepção que as pessoas têm das áreas costeiras e esta percepção varia, em temos sócioeconômicos e culturais, nas diferentes cidades e entre as regiões mais ou menos urbanizadas (MAC LEOD et al., 2002). Esta percepção em geral leva a uma grande valorização do espaço praiano e ao desejo de construir tanto mais próximo da linha de costa quanto possível (DOMURAT, 1987; WICKER, 1996; HALL, 2001). A maioria das construções, feitas sobre ou próximo à linha da costa, altera o delicado equilíbrio entre o suprimento de sedimentos e o poder erosivo das ondas, reduzindo assim a flexibilidade natural da praia (DOYLE et al., 1984; TERICH, 1987).

Com o aumento da demanda por recreação e lazer, e o consequente aumento da pressão sobre os recursos e os ecossistemas naturais, a capacidade de suporte tem sido uma preocupação cada vez mais presente em diversas áreas e em diferentes escalas de avaliação. Segundo Inglis et al. (2000), a capacidade de suporte, ou capacidade de carga de uma determinada região, descreve a relação entre o tamanho da população que dela faz uso e as mudanças causadas pela mesma nos recursos naturais. Para este autor, o conceito de capacidade de suporte assume que existe um determinado número de pessoas que os recursos podem suportar sem que haja a deteriorização da qualidade ambiental.

Este conceito tem sido amplamente utilizado na avaliação do desenvolvimento turístico, representando, neste caso, o ponto além do qual este desenvolvimento levaria a uma deteriorização inaceitável do ambiente físico ou social (ARCHER e COOPER, 2001), ou ainda, de forma mais específica, o número máximo de turistas que podem ser acomodados em uma determinada região (WILLIAMS e GILL, 2001). Contudo, muitas objeções têm sido levantadas quanto ao estabelecimento de um limite fixo para o uso de uma determinada área (MURPHY, 2001; WILLIAMS e GILL, 2001). Uma das questões fundamentais é que este limite não implica, necessariamente, que esta área será utilizada dentro das condições desejadas a fim de minimizar os impactos decorrentes deste uso. De acordo com Murphy (2001) e Williams e Gill (2001), a ênfase deve ser dada para as condições desejáveis para uma área e não para a carga de uso que ela pode

Sociedade \& Natureza, Uberlândia, 21 (1): 71-84, ABR. 2009 
tolerar. Por outro lado, o estabelecimento de parâmetros de tolerância de uso, sejam eles ecológicos, de infra-estrutura ou sociais, geram subsídios importantes para os planos de gestão, permitindo que haja uma diminuição dos impactos decorrentes da atividade turística. Assim, por exemplo, ao se analisar os parâmetros de tolerância social para o uso de uma determinada área, deve ser evidenciada a percepção da comunidade local e dos turistas em relação ao seu próprio nível de aceitabilidade de impactos. Neste contexto, a capacidade de suporte colocaria um limite a partir do qual a comunidade ultrapassaria o seu nível de aceitabilidade de impactos, ou, por outro lado, a atividade turística deixaria de constituir um atrativo devido à sobrecarga gerada pelos próprios usuários. Esta análise deve ser feita no âmbito de uma área limitada, refletindo uma percepção local, e dentro de um período de tempo limitado, pois, como considera Coccossis (2001), os visitantes e a comunidade tendem a mudar de comportamento sob diferentes condições, resultando em diferentes respostas sociais e ambientais.

Pereira da Silva (2002) salienta a importância de se estabelecer a capacidade de suporte social de uma praia como a concentração máxima de pessoas que a mesma pode acomodar sem detrimento da qualidade recreacional dos visitantes e da comunidade local. Como consideram ainda Haggett (2001) e Morgan (1999), a percepção dos visitantes sobre a qualidade ambiental e recreacional pode ser influenciada por diversos fatores que, por sua vez, refletirão em diferentes preferências de usos. Características morfodinâmicas e ambientais, como, a largura e a declividade da praia, a granulometria do sedimento que a compõe e a presença de ondas, muitas vezes determinam o tipo de uso recreacional da praia - por exemplo, praias de areia grossa, estreitas e de declividade acentuada, são menos apreciadas para atividades como jogos e caminhadas. Desta forma, esta percepção representa uma variável dinâmica e diferenciada que pode variar amplamente a depender do tipo de usuário, do local e do período analisado, relativizando, assim, o estabelecimento dos níveis de tolerância.

O bairro de Itapoã está localizado na orla atlântica de Salvador (Fig. 1), numa posição distante do seu centro (tomando como referência o Farol da Barra, a uma distância de aproximadamente 20km), seguindo o vetor norte da cidade. Por seus importantes recursos naturais - como praias, dunas, lagoas e coqueirais - e grande valor cultural, Itapoã criou um capital simbólico próprio que o destaca dos outros bairros de Salvador, tendo sido um dos principais locais de veraneio em meados do século passado (SOUZA, 2005). Nas últimas décadas, o bairro de Itapoã vem sofrendo uma grande explosão demográfica, passando de 23.782 habitantes, em 1980, para 88.600 habitantes, em 2000, com um incremento de $372,6 \%$, segundo dados do IBGE, representando um aumento muito superior ao da cidade como um todo, que, neste mesmo período, cresceu cerca de 162\% (IBGE, 2007). Estes dados refletem uma urbanização acelerada, com grande aumento na construção de loteamentos e construções irregulares, que acentua problemas estruturais, como a falta de saneamento básico, e traz graves consequências para a região costeira, como a superlotação das praias, poluição e supressão da vegetação nativa. 


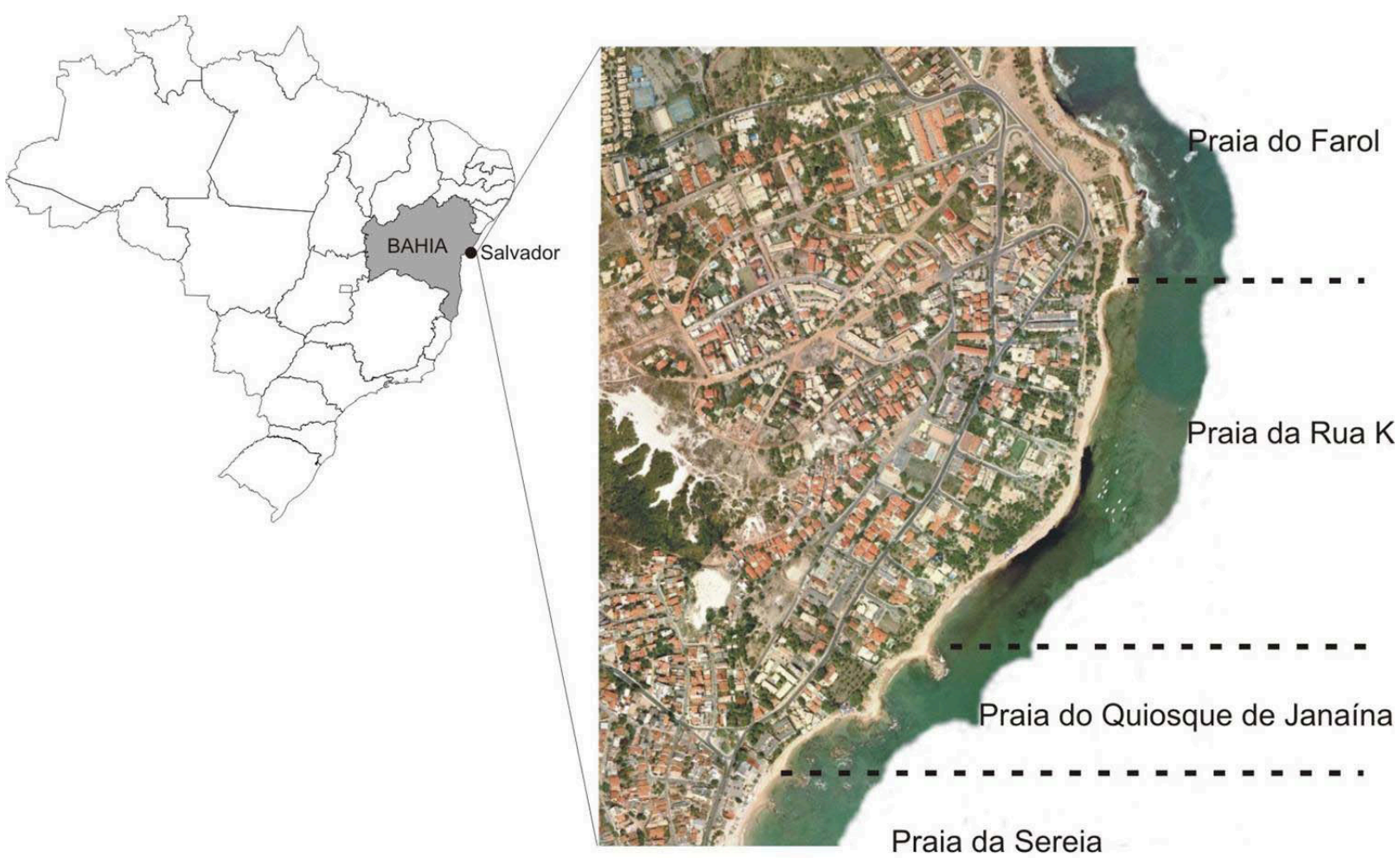

Fonte: CONDER, 2006

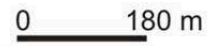

Figura 1. Localização das praias do bairro de Itapoã, Salvador, Bahia

Neste contexto, as praias do bairro de Itapoã representam uma das poucas opções de recreação e lazer para os moradores do próprio bairro e de bairros vizinhos, especialmente para a população de baixa renda. Desta forma, este artigo pretende avaliar a capacidade de suporte das praias do bairro de Itapoã, de acordo com os limites de tolerância dos seus usuários, fornecendo subsídio para a sua gestão sócioambiental.

\section{Material e Métodos}

A caracterização do ambiente costeiro foi realizada no mês de fevereiro de 2008, quando todas as praias do bairro de Itapoã, entre as praias da Sereia e do Farol, foram percorridas a pé e suas principais características foram descritas em uma ficha padrão. Nesta foram indicados o tipo de construções fixas à beira mar e de barracas de praia, a ocorrência de evidências de erosão, a declividade e a largura da face da praia, a granulometria dos sedimentos, a ocorrência de lixo e esgoto, a altura das ondas e a presença de afloramentos rochosos.

Durante um final de semana, a praia da Rua $\mathrm{K}$, uma das mais frequentadas do bairro, foi fotografada no horário das 8:00 às 18:00 horas, a cada hora, a fim de possibilitar a identificação do fluxo de banhistas durante o dia, sendo considerado o horário de maior fluxo de turistas, verificado nesta praia, como referência para todo o trecho costeiro estudado. As praias ao longo do trecho estudado foram segmentadas em 55 células de $30 \mathrm{~m}$ de comprimento (compreendendo as zonas do berma ou pós-praia e da face da praia) e medidas, em cada uma delas, as suas larguras inicial e final. Em cada célula foi então realizada a contagem do número de pessoas. Para essa contagem, as caminhadas foram realizadas no horário de maior frequência, identificado a partir das fotografias. Buscou-se sempre realizar esta contagem, bem como as medidas de cada célula de praia, nos dias em que este horário correspondia a alturas de 
Diagnóstico ambiental e avaliação da capacidade de suporte das praias do bairro de Itapoã, Salvador, Bahia Iracema Reimão Silva, José Rodrigues de Souza Filho, Merissa Andrade Leite Barbosa, Fádia Rebouças, Ricardo Augusto Souza Machado

marés durante ou próximas à baixa-mar. Foi então calculada a relação entre a área de cada célula e o número de frequentadores, encontrando, assim, a área, em metros quadrados, de praia disponível para cada banhista/recreacionista. A contagem dos freqüentadores foi realizada nas zonas denominadas ativa (face da praia, local próximo ao mar e usado, por exemplo, para a prática de jogos como frescobol) e solarium (berma, local onde as pessoas tomam banho de sol e usam cadeiras e sombreiros) (POLLETE e RAUCCI, 2003).

Foram realizadas 437 entrevistas intencionais a fim de estimar a preferência dos usuários acerca da escolha da praia e da disponibilidade do espaço praiano. Durante estas entrevistas os usuários indicaram se estavam satisfeitos com a quantidade de pessoas acomodadas naquela praia, se a praia poderia acomodar ainda mais pessoas (até o dobro do número atual de banhistas/recreacionistas) ou se o ideal para eles seria um número menor de pessoas (a metade do número atual de banhistas/ recreacionistas).

\section{Resultados e discussões}

O bairro de Itapoã apresenta em torno de 1,5 km de praia, entre a Praia da Sereia e a Praia do Farol (Fig. 1). Ao longo de todo esse trecho a zona costeira adjacente encontra-se alterada pela retirada da vegetação nativa, com a construção, de maneira quase que contínua, de casas, pousadas, restaurantes e barracas de praia com estrutura de alvenaria (Fig. 2). Estas construções, como dito anteriormente, podem alterar o equilíbrio da sedimentação costeira e a mobilidade da faixa arenosa, aumentando a sua suscetibilidade a eventos erosivos.

O aumento dos processos erosivos associados à existência de construções fixas representa um problema ambiental e social na medida em que estas construções impedem o livre recuo da linha de costa, passando a representar assim um risco à infraestrutura costeira e reduzindo a capacidade recreacional da praia (BIRD, 1985; PILKEY, 1991; LIZÁRRAGA-ARCINEIGA et al., 2001). No caso de Itapoã, o potencial erosivo das ondas é diminuído pela existência de afloramentos rochosos do embasamento cristalino de Salvador (Fig. 3) que servem como anteparo à ação das ondas, especialmente durante os períodos de maré baixa. Ao longo das praias, durante o período estudado, foi verificada a existência de muros, alguns para proteção da atuação das ondas, e de estruturas de proteção feitas com troncos de madeira. Esta situação pode ser agravada caso se confirme a perspectiva de subida do nível do mar, devido a um aquecimento global, que poderá contribuir para o aumento do poder erosivo das ondas, através de um aumento na frequência de incidência e na magnitude das tempestades tropicais, que passariam inclusive a incidir na região leste-nordeste brasileira, aumentando, segundo Spencer (1995), em mais de $60 \%$ o potencial destrutivo das mesmas, através da sobreelevação da altura das ondas por marés meteorológicas (FLICK, 1998). Neste cenário, a atenuação da energia das ondas devido aos afloramentos rochosos pode ser desprezível e o impedimento do livre recuo da faixa arenosa pela existência das construções fixas pode representar a perda da praia recreativa, como já acontece em muitos trechos da costa baiana e brasileira.

As praias localizadas em regiões metropolitanas estão muito susceptíveis à poluição, em diversas formas, comprometendo o seu uso para a pesca e atividades recreacionais. No manejo de praias é essencial o conhecimento das implicações negativas da poluição e do nível de tolerância por parte dos frequentadores. Não ocorre descarga de esgoto doméstico nas praias estudadas, apenas escoamento de águas pluviais (Fig. 4). A ocorrência de lixo ao longo das praias também é uma clara evidência de poluição e de utilização deste ambiente sem que se tenha compromisso com a preservação da sua qualidade. Foi encontrado lixo (papeis, garrafas, plásticos, etc) em todas as praias de Itapoã. Além do lixo, foi encontrada uma grande quantidade de algas distribuídas ao longo da face da praia (Fig. 5). A presença destas algas, assim como a presença do lixo, diminui a atratividade destas praias para o banho e para a recreação. Contudo, as praias do bairro de 
Itapoã apresentam, de um modo geral, características propícias para atividades recreacionais, como boa qualidade da água para banho, baixo nível de turbidez das águas, pequena altura de ondas, granulometria

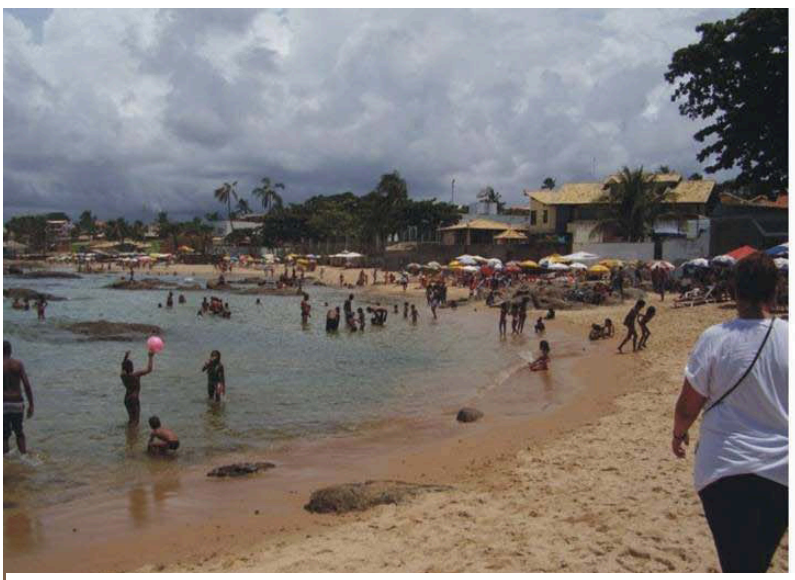

Foto 1. Alteração da paisagem natural ao longo das praias

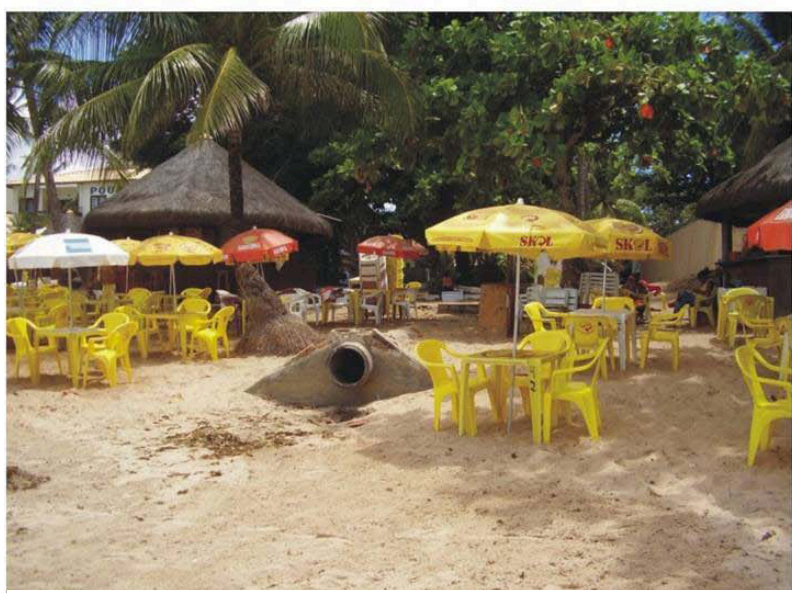

Foto 3. Canal para escoamento de água pluvial

Em relação à percepção dos usuários, cerca de $34 \%$ dos entrevistados indicaram a sujeira como o maior problema encontrado, $25 \%$ indicaram problemas relacionados à infra-estrutura e ao atendimento nas barracas, $24 \%$ não indicaram nenhum problema, 6,4\% indicaram ausência de segurança, $3 \%$ a presença de afloramentos rochosos, $1,4 \%$ a existência de esgoto, $1 \%$ ausência de salvavidas, dentre outros (Gráf. 1).

A facilidade de acesso é um dos fatores de areia fina a média, bom acesso e presença de barracas de praia (LEATHERMAN, 1997; SILVA et al., 2003).

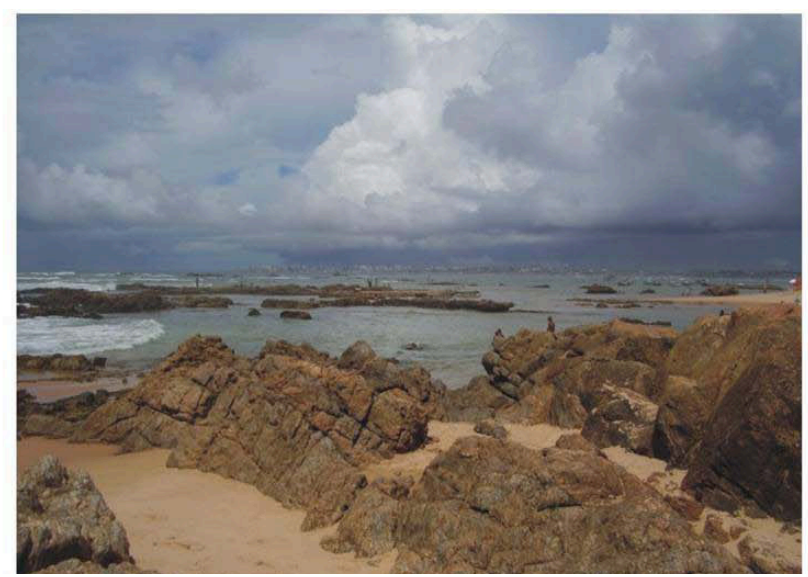

Foto 2. Presença de rochas do embasamento cristalino de Salvador

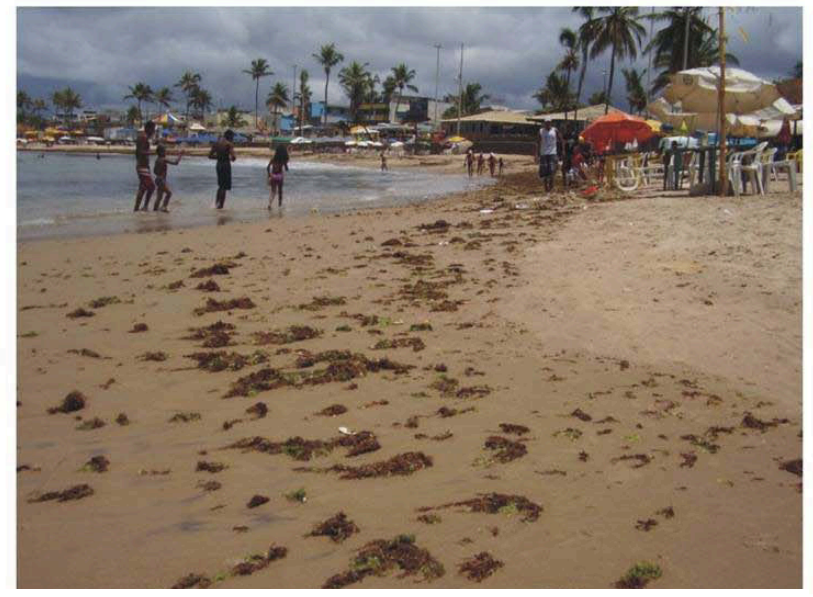

Foto 4. Presença de algas ao longo das praias

fundamentais na determinação do nível de frequência de uma praia (SILVA et al., 2003; SILVA et al., 2007). Para as praias de Itapoã, como na maioria das praias localizadas em áreas urbanas, o acesso é facilitado pela disponibilidade de transportes coletivos. Durante as entrevistas, a localização e o acesso foram indicados por $24 \%$ dos banhistas/recreacionistas como o principal fator que motivou a sua escolha pelas praias do bairro de Itapoã, sendo a maior parte dos frequentadores morados do bairro ou das suas proximidades (Gráf. 2). As entrevistas indicaram também que cerca 
de $34 \%$ dos frequentadores consultados consideraram a tranquilidade como seu principal fator de escolha. Esta referência à tranqüilidade das praias de Itapoã representa, em grande parte, como salientam Afonso e Serpa (2007), uma idealização do bairro no imaginário popular, e que, apesar do quadro atual de degradação ambiental e conflitos sociais, ainda está presente na maior parte dos entrevistados.

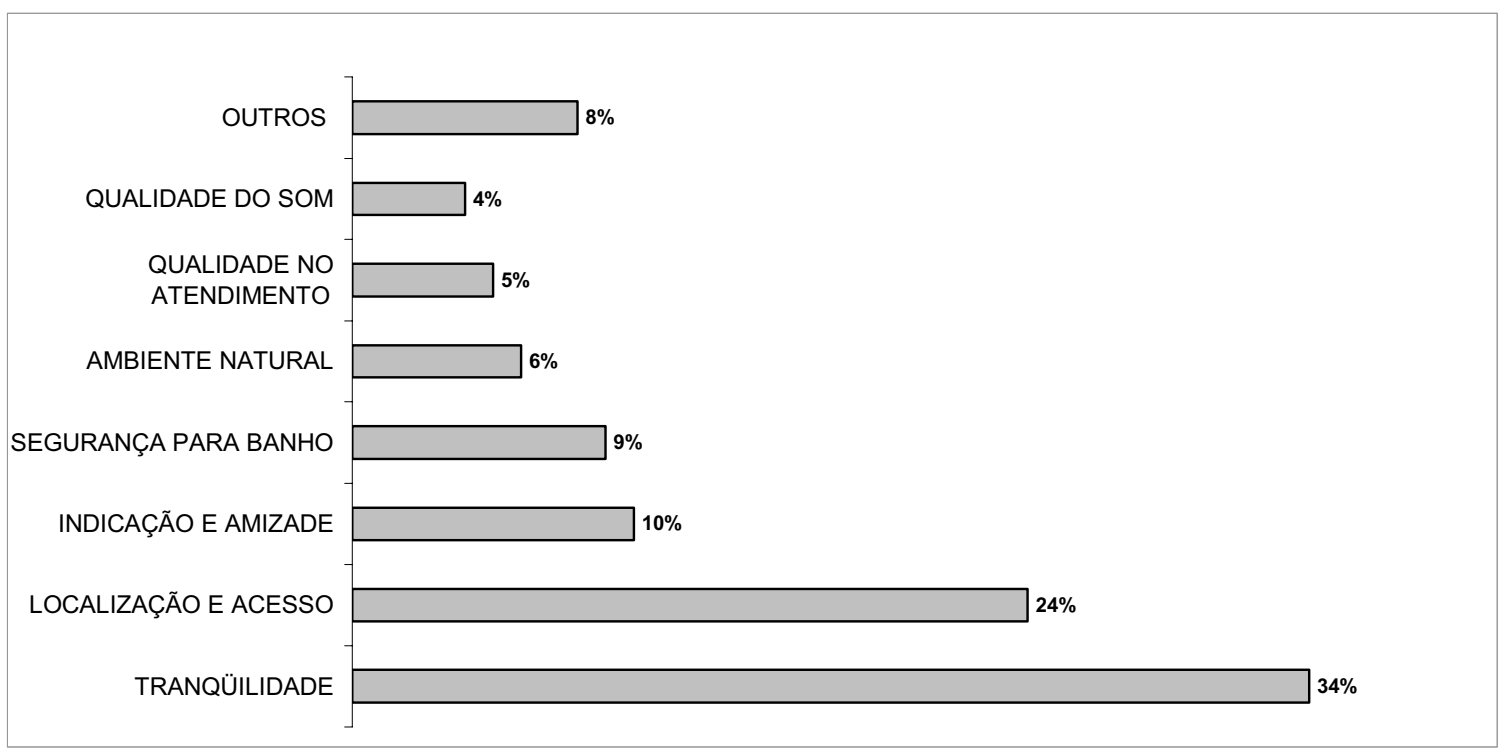

Gráfico 1. Principais problemas indicados pelos freqüentadores das praias do bairro de Itapoã

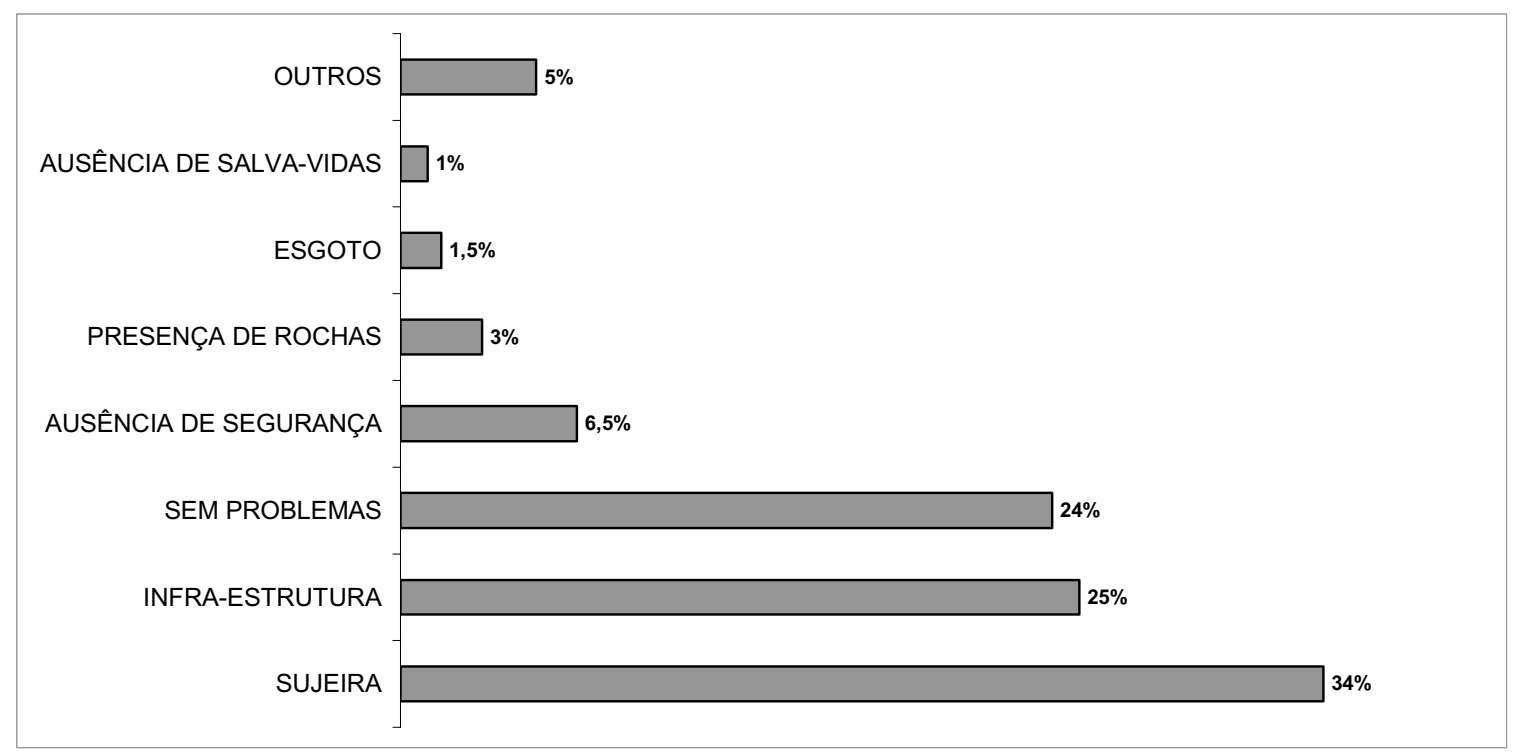

Gráfico 2. Principais fatores determinantes da escolha das praias do bairro de Itapoã na opinião dos freqüentadores entrevistados

As fotografias tiradas a cada hora, entre 8:00 e 18:00h (Fig. 6), indicaram uma maior frequência de usuários no horário entre 13:00 e 17:00h. Desta forma, de acordo com a metodologia adotada, esse horário foi considerado como de maior concentração de usuários, servindo como referência para a 
contagem do número máximo de banhistas/ recreacionistas por célula. O número de banhistas/ recreacionistas por célula variou de 12 a 245 , ficando a maior parte delas com valores entre 50 e 100 . A concentração de usuários ao longo das praias de Itapoã varia principalmente de acordo com a existência de barracas. Os trechos com menor concentração de usuários correspondem a trechos sem a disponibilidade de barracas de praia (Fig. 7), e os de maior concentração correspondem, em geral, aos trechos onde estão localizados as barracas mais populares (Fig. 8).

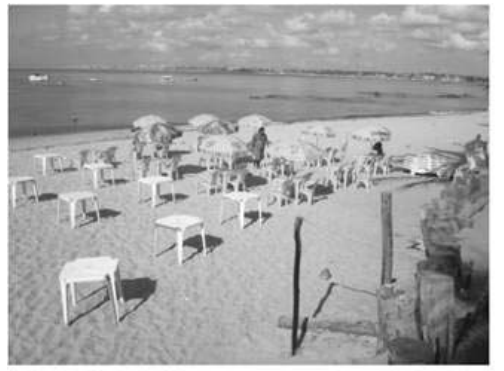

$8: 00 \mathrm{~h}$

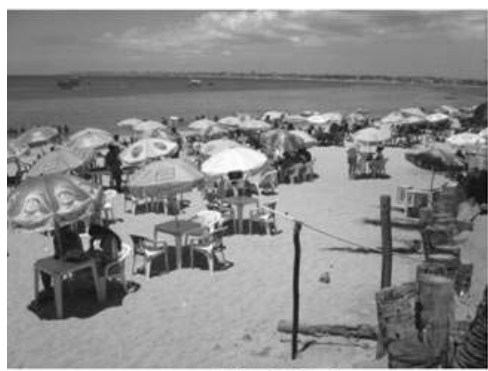

$11: 00 \mathrm{~h}$

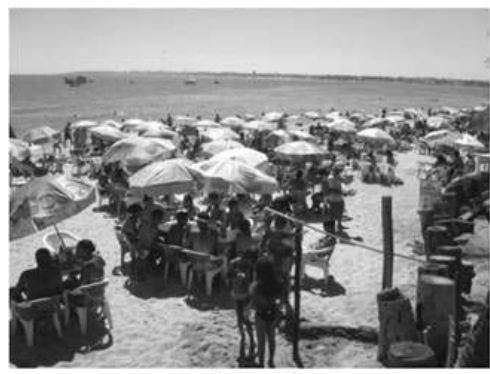

$14: 00 \mathrm{~h}$

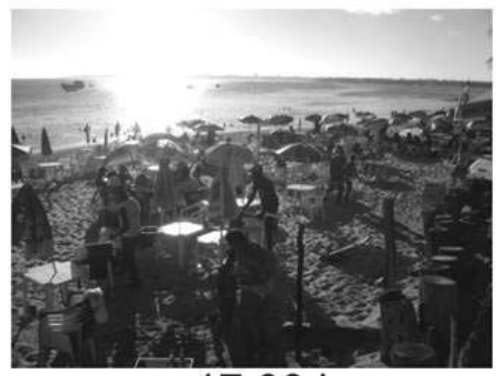

$17: 00 \mathrm{~h}$

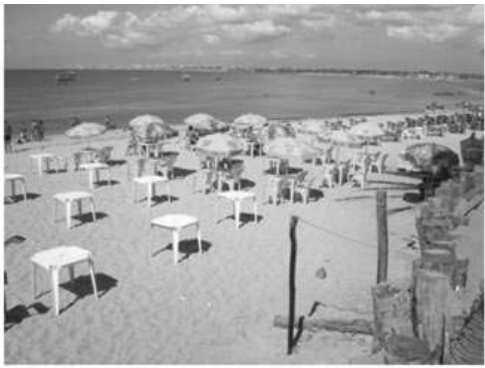

9:00 h

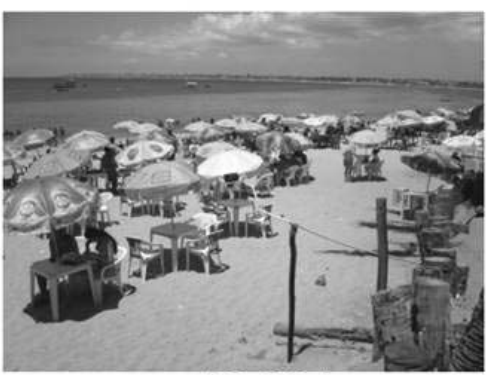

$12: 00 \mathrm{~h}$

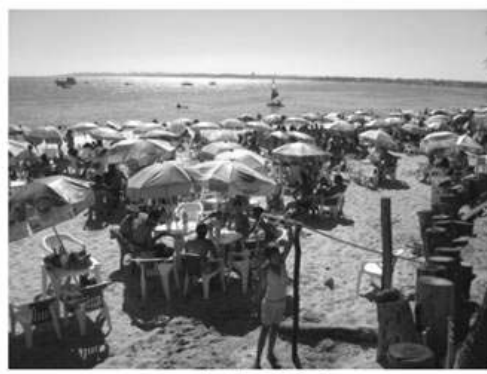

$15: 00 \mathrm{~h}$

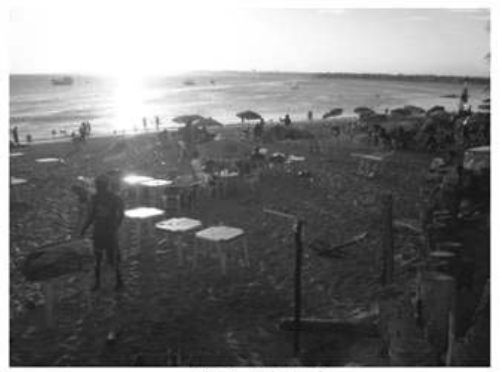

$18: 00 \mathrm{~h}$

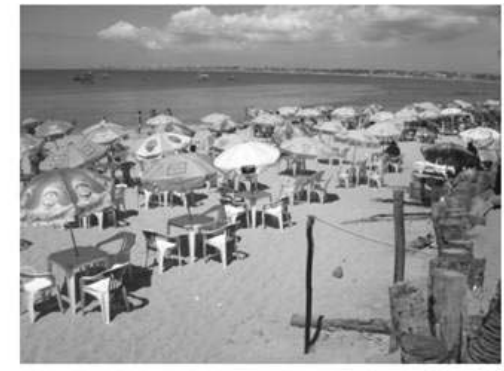

$10: 00 \mathrm{~h}$

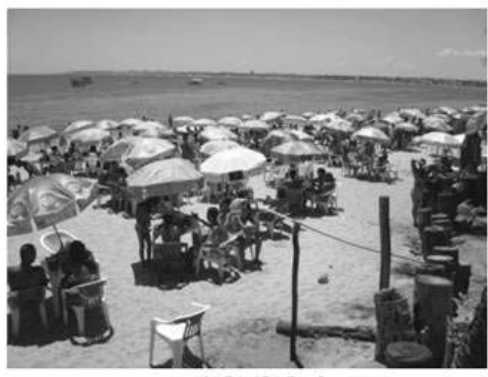

$13: 00 \mathrm{~h}$

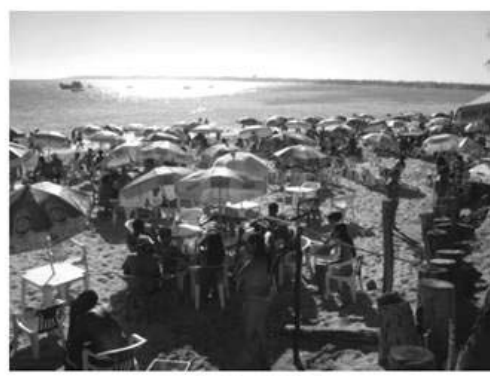

$16: 00 \mathrm{~h}$

Figura 6. Variação da ocupação da praia da Rua K no período entre 8:00 e 18:00 h 


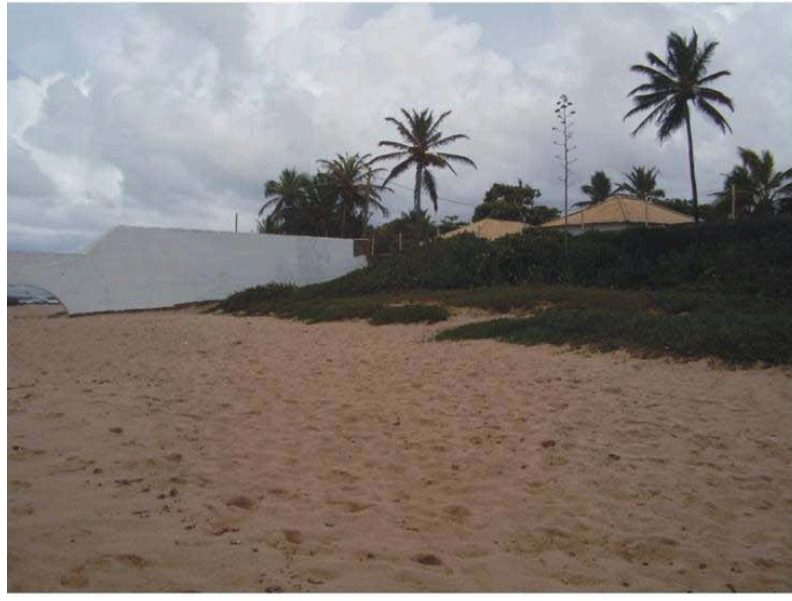

Figura 7. Ausência de barrracas ao norte da pria do Farol

A estimativa da capacidade de suporte de uma praia requer a identificação da área de praia disponível para propostas recreacionais, medida, nesta pesquisa, a partir dos dados de largura das zonas de face da praia e berma ou pós-praia. A tabela 1 apresenta a área e o número de banhistas/recreacionistas encontrados em cada célula, conforme a metodologia descrita anteriormente. Os valores de área de praia disponível para cada banhista/recreacionista foram agrupados em quatro categorias: nível de uso intenso ( $49 \%$ das células), médio ( $36 \%$ das células), baixo ( $4 \%$ das células) e muito baixo ( $11 \%$ das células), correspondendo, respectivamente, a valores de 4 a 10 , de 11 a 20 , de 21 a 50 e acima de $50 \mathrm{~m}^{2}$ por banhista/recreacionista (Tab.; Fig. 9).

A categoria aqui definida como de uso intenso (4 a $10 \mathrm{~m}^{2}$ por banhista) pode ser considerada como o limite de tolerância para os usuários destas praias. A maioria dos usuários entrevistados (80\%) disse estar satisfeito com a área disponível para suas atividades de recreação e lazer, mas não gostaria que essa área fosse inferior a atual. Desta forma, um aumento no uso destas praias, o que implicaria em uma diminuição na área disponível para cada banhista/recreacionista, ocasionaria, possivelmente, uma perda da atratividade

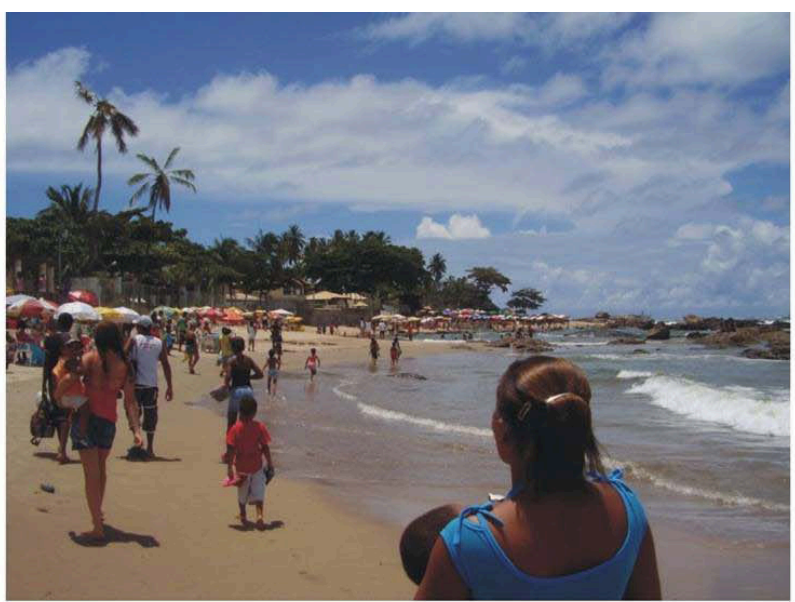

Figura 8. Presença de barracas na praia do Quiosque de Janaína

devido à sobrecarga gerada pelos próprios usuários. Esse valor máximo de tolerância está compatível com os valores encontrados, por exemplo, por Silva et al. (2008), para as praias do município de Porto Seguro, que, segundo a percepção dos usuários, apresentaram um nível de uso ideal na faixa de 6 a $10 \mathrm{~m}^{2}$ por banhista/recreacionista e Pereira da Silva (2002), que considera como um valor máximo tolerável para a capacidade de suporte, para praias de maneira geral, em torno de 3 a $5 \mathrm{~m}^{2} /$ pessoa.

Algumas limitações precisam ser consideradas. Deve-se levar em conta que, como advertem Polette e Raucci (2003), muitos problemas resultantes do uso recreacional das praias podem não ser devidos ao número de usuários e, sim, ao seu comportamento, e que o nível de uso ideal das praias, segundo a percepção dos usuários, depende de muitas características relacionadas ao indivíduo, não consideradas no presente trabalho, tais como, idade, tipo de personalidade, sexo, e as características cultural e ocupacional (EDNEY e JORDAN-EDNEY apud DE RUICK et al., 1997; MAC LEOD et al. 2002). Além disso, essa percepção varia temporal e espacialmente, refletindo apenas a opinião dos usuários no período em que foi realizada a pesquisa. 
Diagnóstico ambiental e avaliação da capacidade de suporte das praias do bairro de Itapoã, Salvador, Bahia Iracema Reimão Silva, José Rodrigues de Souza Filho, Merissa Andrade Leite Barbosa,

Fádia Rebouças, Ricardo Augusto Souza Machado

Tabela. Nível de uso das praias do bairro de Itapoã em fevereiro de 2008

\begin{tabular}{|c|c|c|c|c|c|}
\hline \multirow{13}{*}{$\begin{array}{l}\text { Praia do } \\
\text { Farol }\end{array}$} & Células & \begin{tabular}{|c|} 
Número de banhistas $/$ \\
recreacionistas em \\
cada célula de $30 \mathrm{~m}$ de \\
comprimento
\end{tabular} & $\begin{array}{c}\text { Área de praia } \\
\text { disponível para } \\
\text { acomodação de } \\
\text { banh./rec. }\left(\mathbf{m}^{2}\right)\end{array}$ & $\begin{array}{c}\text { Nível de uso atual por } \\
\text { praia (área média } \\
\text { utilizada por banh./rec.) } \\
\left(\mathrm{m}^{2}\right)(\text { fevereiro/2008) }\end{array}$ & $\begin{array}{c}\text { Classificação do } \\
\text { nível de uso } \\
\text { atual }\end{array}$ \\
\hline & 1 & 79 & 735 & 9 & intenso \\
\hline & 2 & 49 & 585 & 12 & médio \\
\hline & 3 & 75 & 1140 & 15 & médio \\
\hline & 4 & 89 & 1485 & 17 & médio \\
\hline & 5 & 139 & 1365 & 10 & intenso \\
\hline & 6 & 55 & 1140 & 21 & baixo \\
\hline & 7 & 151 & 900 & 6 & intenso \\
\hline & 8 & 81 & 1020 & 13 & médio \\
\hline & 9 & 63 & 1140 & 18 & médio \\
\hline & 10 & 72 & 1005 & 14 & médio \\
\hline & 11 & 89 & 900 & 10 & intenso \\
\hline & 12 & 40 & 825 & 21 & baixo \\
\hline \multirow{26}{*}{$\begin{array}{l}\text { Praia da } \\
\text { Rua K }\end{array}$} & 13 & 56 & 1050 & 19 & médio \\
\hline & 14 & 86 & 1365 & 16 & médio \\
\hline & 15 & 90 & 1560 & 17 & médio \\
\hline & 16 & 59 & 1410 & 24 & baixo \\
\hline & 17 & 117 & 1140 & 10 & intenso \\
\hline & 18 & 64 & 1065 & 17 & médio \\
\hline & 19 & 5 & 1020 & 204 & muito baixo \\
\hline & 20 & 8 & 1005 & 126 & muito baixo \\
\hline & 21 & 16 & 960 & 60 & muito baixo \\
\hline & 22 & 12 & 960 & 80 & muito baixo \\
\hline & 23 & 12 & 930 & 78 & muito baixo \\
\hline & 24 & 98 & 930 & 9 & intenso \\
\hline & 25 & 73 & 1050 & 14 & médio \\
\hline & 26 & 184 & 1140 & 6 & intenso \\
\hline & 27 & 144 & 1140 & 8 & intenso \\
\hline & 28 & 102 & 1260 & 12 & médio \\
\hline & 29 & 78 & 1350 & 17 & médio \\
\hline & 30 & 239 & 1155 & 5 & intenso \\
\hline & 31 & 165 & 855 & 5 & intenso \\
\hline & 32 & 154 & 720 & 5 & intenso \\
\hline & 33 & 10 & 720 & 72 & muito baixo \\
\hline & 34 & 69 & 840 & 12 & médio \\
\hline & 35 & 66 & 840 & 13 & médio \\
\hline & 36 & 76 & 780 & 10 & intenso \\
\hline & 37 & 121 & 870 & 7 & intenso \\
\hline & 38 & 108 & 975 & 9 & intenso \\
\hline & 39 & 183 & 975 & 5 & intenso \\
\hline & 40 & 106 & 945 & 9 & intenso \\
\hline & 41 & 228 & 990 & 4 & intenso \\
\hline
\end{tabular}


Diagnóstico ambiental e avaliação da capacidade de suporte das praias do bairro de Itapoã, Salvador, Bahia Iracema Reimão Silva, José Rodrigues de Souza Filho, Merissa Andrade Leite Barbosa, Fádia Rebouças, Ricardo Augusto Souza Machado

\begin{tabular}{|c|c|c|c|c|c|}
\hline \multirow{10}{*}{$\begin{array}{l}\text { Praia do } \\
\text { Quiosque } \\
\text { de Janaína }\end{array}$} & Células & $\begin{array}{c}\text { Número de banhistas } / \\
\text { recreacionistas em } \\
\text { cada célula de } 30 \mathrm{~m} \text { de } \\
\text { comprimento }\end{array}$ & $\begin{array}{l}\text { Área de praia } \\
\text { disponível para } \\
\text { acomodação de } \\
\text { banh./rec. }\left(\mathbf{m}^{2}\right)\end{array}$ & $\begin{array}{c}\text { Nível de uso atual por } \\
\text { praia (área média } \\
\text { utilizada por banh./rec.) } \\
\left(\mathrm{m}^{2}\right)(\text { fevereiro/2008) }\end{array}$ & $\begin{array}{c}\text { Classificação do } \\
\text { nível de uso } \\
\text { atual }\end{array}$ \\
\hline & 42 & 245 & 945 & 4 & intenso \\
\hline & 43 & 134 & 825 & 6 & intenso \\
\hline & 44 & 189 & 780 & 4 & intenso \\
\hline & 45 & 213 & 780 & 4 & intenso \\
\hline & 46 & 157 & 750 & 5 & intenso \\
\hline & 47 & 74 & 705 & 10 & intenso \\
\hline & 48 & 57 & 540 & 9 & intenso \\
\hline & 49 & 57 & 510 & 9 & intenso \\
\hline & 50 & 64 & 660 & 10 & intenso \\
\hline \multirow{5}{*}{$\begin{array}{l}\text { Praia da } \\
\text { Sereia }\end{array}$} & 51 & 48 & 810 & 17 & médio \\
\hline & 52 & 54 & 735 & 14 & médio \\
\hline & 53 & 54 & 645 & 12 & médio \\
\hline & 54 & 33 & 645 & 20 & médio \\
\hline & 55 & 91 & 615 & 7 & intenso \\
\hline
\end{tabular}

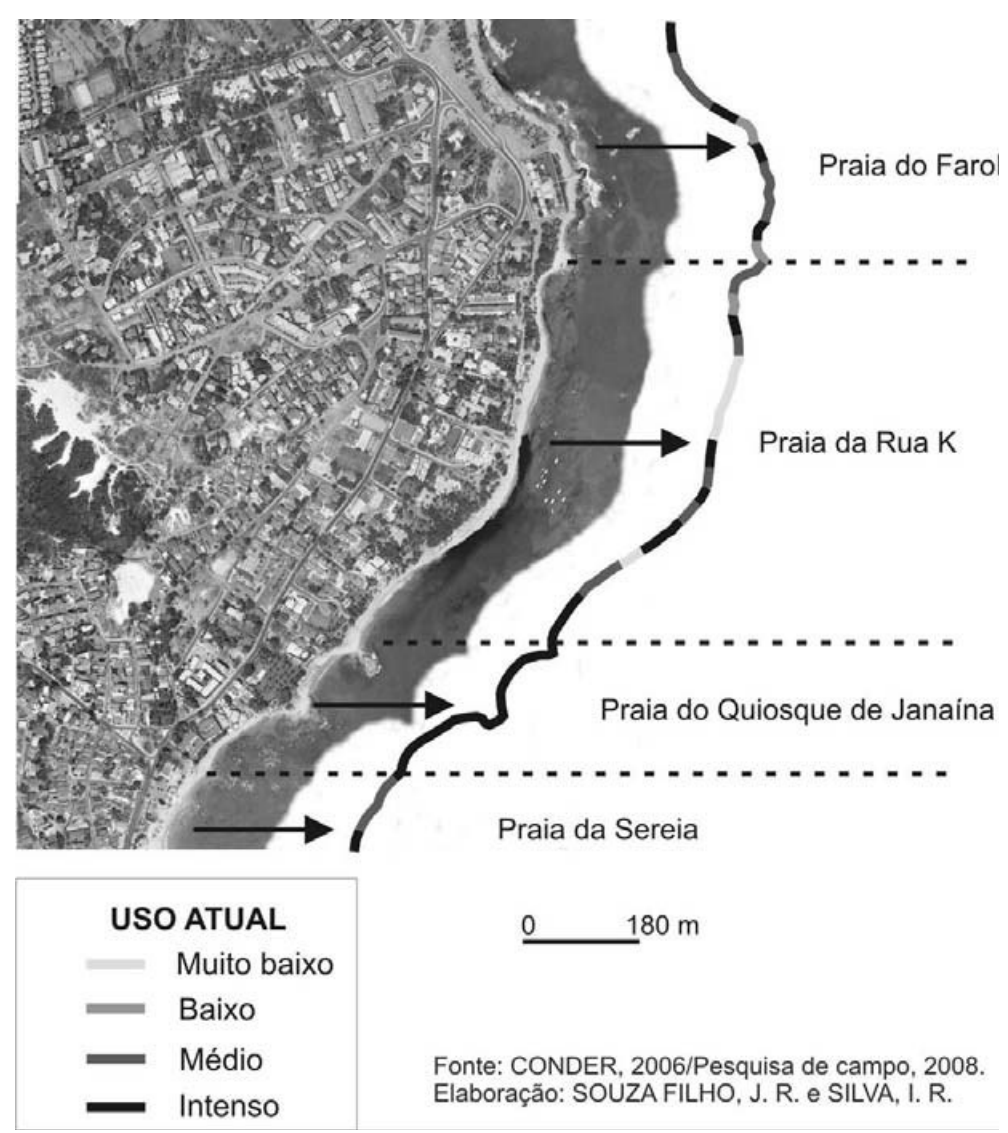

Figura 9. Uso das praias de Itapoã em fevereiro de 2008: intenso ( 4 a $10 \mathrm{~m}^{2}$ por banhista/recreacionista), médio (11 a 20 $\mathrm{m}^{2}$ por banhista/recreacionista), baixo (21 a $50 \mathrm{~m}^{2}$ por banhista/recreacionista) e muito baixo (acima de $50 \mathrm{~m}^{2}$ por banhista/ recreacionista) 


\section{Considerações Finais}

A capacidade de suporte está diretamente ligada a parâmetros de tolerância social e ao nível de aceitabilidade de impactos que a comunidade ou os turistas têm para uma determinada área. A maior parte das praias do bairro estudado apresentou um uso intenso, com 4 a $10 \mathrm{~m}^{2}$ por banhista/recreacionista, aqui considerado como o limite de tolerância para os usuários destas praias. Durante as entrevistas, a sujeira e a falta de estrutura das barracas foram os principais problemas apontados, enquanto que, a facilidade de acesso e a tranquilidade foram os principais atrativos para a maior parte dos entrevistados.

O bairro de Itapoã, que sempre teve grande destaque por seus recursos naturais e valor cultural, atualmente mostra um cenário grave de degradação ambiental. A ocupação desordenada, a retirada da vegetação nativa e a poluição alteram o seu ecossistema costeiro e podem comprometer o valor recreacional de suas praias. Neste contexto, este artigo contribui fornecendo subsídios para a sua gestão sócio-ambiental, contudo, como foi dito anteriormente, esses dados são dinâmicos e devem ser atualizados e aprofundados em alguns aspectos não abordados nesta pesquisa.

\section{Referências}

AFONSO, L. D.; SERPA, A. S. P. Perfil socioeconômico e cultural do bairro de Itapuã em Salvador-BA. In: Colóquio Nacional do Núcleo de Estudos em Espaço e Representações - NEER, 2., dez/2007, Salvador: UFBA/UFPR, 2007.

ARCHER, B. \& COOPER, C. Os Impactos positivos e negativos do turismo. In: THEOBALD, W. F. (org). Turismo Global. São Paulo: Editora Senac. 2001. 510p. (p.85-102)

BIRD, E. C. F. Coastline Changes. A Global Review. Chichester: J. Wiley, 1985.

COCCOSSIS, H. 2001. Defining, measuring and evaluating carrying capacity in European tourism destinations. Final Report. Department of Environmental Studies, University of the Segean, Athens. Disponível em: http://europa.eu.int/comm/ environment $/ \mathrm{iczm} / \mathrm{pdf} / \mathrm{tccamaterial}$.pdf Acesso em: 10 de maio 2006.

DOMURAT, G. W. Beach Nourishment - A Working Solution. Shore \& Beach, v. 55, n.3/4, p. 92 - 95, 1987.

DOYLE, L. J.; SHAWMA, D. C.; HIM, A. C.; PILKEY Jr., O. H.; NEA, W. J.; PILKEY, O. H.; MARTIN, D., BELKNAP, D. F. Living with the West Florida shore. In: PILKEY Jr. O. H. and NEAL W. I. (eds) Living with the shore. North Carolina, U.S.A.: Duke University Press, 1984, 255p.

ERGIN, A.; WILliAMS, A. T.; MICALEFF, A. Coastal Scenary: Appreciation and Elaluation. Journal of Coastal Research, v. 22, n. 4, p. 958-964, 2006.

FLICK, R. E. Comparison of California tides, storm surges and mean sea level during the El Niño winters of 1982-1983 and 1997-1998. Shore \& Beach, v. 63, p. 7-11, 1998.

HAGGETT, P. Geography: A Global Synthesis. Harlow: Prentice Hall. 2001.

HALL, C. M. Trends in ocean and coastal tourism: the end of the last frontier? Ocean \& Coastal Management, v. 44, p. 601-618, 2001.

IBGE - Instituto Brasileiro de Geografia e Estatística - Censo 2007. Disponível em http://www.ibge.gov.br. Acesso em 06 de maio de 2007.

INGLIS, G. J.; HAYDEN, B. J.; ROSS, A. H. An overview of factors affecting the carrying capacity of coastal embayment for mussel culture. 2000. Disponível em: http://govdocs.aquake.org/cgi/reprint/ 2004. Acesso em: 20 de setembro de 2006.

KULLENBERG, G. Contributions of marine and coastal area research and observations towards

Sociedade \& Natureza, Uberlândia, 21 (1): 71-84, ABR. 2009 
Diagnóstico ambiental e avaliação da capacidade de suporte das praias do bairro de Itapoã, Salvador, Bahia Iracema Reimão Silva, José Rodrigues de Souza Filho, Merissa Andrade Leite Barbosa, Fádia Rebouças, Ricardo Augusto Souza Machado

sustainable development of large coastal cities. Ocean \& Coastal Management, v. 44, p. 283-291, 2001.

LEATHERMAN, S. P. Beach Rating: A Methodological Approach. Journal of Coastal Research, v. 13, n. 1, p. $253-258,1997$.

LIZÁRRAGA-ARCINIEGA, R.; APPENDINIALBRETCHSEN, C. M.; FISCHER, D. W. Planning for Beach Erosion: A Case Study, Playas de Rosarito, B. C. Mexico. Journal of Coastal Research, v. 17, n. 3, p. 636-644, 2001.

MAC LEOD, M.; SILVA, C. P. da; COOPER, J. A. G. A Comparative Study of the Perception and Value of Beaches in Rural Ireland and Portugal: Implications for Coastal Zone Management. Journal of Coastal Research, v. 18, n. 1, p. 14-24, 2002.

MIDAGLIA, C. L. V. Turismo e Meio Ambiente no Litoral Paulista: Dinâmica da Balneabilidade das Praias. In: LEMOS, A. I. G. (Ed.), Turismo: Impactos Socioambientais. São Paulo: Editora HUCITEC, 2001. p. 33-56.

MORGAN, R. Preferences and Priorities of Recreational of Beach Users in Wales, UK. Journal of Coastal Research, v. 15, n. 3, p. 653-667, 1999.

MURPHY, P. E. Turismo e Desenvolvimento Sustentado. In: THEOBALD, W. F. (org). Turismo Global. São Paulo: Editora Senac. 2001. 510p. (p.187 -203)

POLETTE, M.; RAUCCI, G. D. Metodological Proposal for Carrying Capacity Analysis in Sandy Beaches: A Case Study at the Central Beach of Balneário Comboriú (Santa Catarina, Brazil). Journal of Coastal Research, SI 35, p. 94-106, 2003.

PEREIRA da SILVA, C.. Beach Carrying Capacity Assessment: How important is it? Journal of Coastal Research, SI 36, p.190-197, 2002.

PILKEY, O. H., Coastal Erosion. Episodes. International Geoscience News Magazine, v. 14, n. 1, p. 45-51, 1991.
RUYCK, M. C. de; SOARES, A. G.; MCLACHLAN, A. Social Carrying Capacity as a Management Tool for Sandy Beaches. Journal of Coastal Research, v. 13, n. 3, p. 822-830, 1997.

SILVA I. R., BITTENCOURT A.C.S.P., DOMINGUEZ J.M.L, SILVA, S. B. M. Uma Contribuição à Gestão Ambiental da Costa do Descobrimento (Litoral Sul do Estado da Bahia): Avaliação da Qualidade Recreacional das Praias. Geografia, v. 28, n. 3, p. $397-414,2003$.

SILVA I. R., BITTENCOURT A.C.S.P., DOMINGUEZ J.M.L, SILVA, S. B. M. Pontencial de Danos Econômicos Face à Erosão Costeira, Relativo às Praias da Costa do Descobrimento Litoral Sul do Estado da Bahia. Pesquisas em Geociências, v. 34, n.1, p. 35 - 44, 2007.

SILVA I. R., BITTENCOURT A.C.S.P., SILVA, S. B. M., DOMINGUEZ J.M.L, SOUZA FILHO, J. R. Nível de antropização $\mathrm{X}$ nível de uso das praias de Porto Seguro/BA: subsídios para uma avaliação da capacidade de suporte. Gestão Costeira Integrada, v. 8, n. 1, p. $1-13,2008$.

SOUZA, Fabio A. M. C. de. O bairro de Itapuã e o descompasso entre sua urbanização e a qualidade de vida local. In: Semana de Mobilização Científica SEMOC, 8., 2005, Salvador: UCSal, 2005.

SPENCER, T. Potentialities, uncertainties and complexities in the response of coral reefs to future sea-level rise. Earth Surface Processes and Landforms, v. 20, p. $49-64,1995$.

TERICH, T. A. 1987. Living with the shore of Puget Sonud and the Georgia Strait. In: PILKEY Jr. O. H. and NEAL W. I. (eds) Living with the shore. North Carolina, U.S.A.: Duke University Press, 1984, p. 250-255.

VERA, J. F.; PALOMEQUE, F.L.; MARCHENA, M.J.; ANTON, S. Análisis Territorial del Turismo. Barcelona: Ariel, 1997. 
Diagnóstico ambiental e avaliação da capacidade de suporte das praias do bairro de Itapoã, Salvador, Bahia

Iracema Reimão Silva, José Rodrigues de Souza Filho, Merissa Andrade Leite Barbosa,

Fádia Rebouças, Ricardo Augusto Souza Machado

WICKER, C. F. Problems of the New Jersey Beaches.

Shore \& Beach, v. 34, n. 1, p. 3 - 8, 1996.

WILliAMS, P. W. \& GILL, A. Questões de Gerenciamento da Capacidade de Carga Turística. In: THEOBALD, W. F. (org). Turismo Global. São Paulo: Editora Senac, 2001. p. $245-265$. 